\title{
Analyzing the Effect of Cooling System on Temperature Using Modeling and Simulation with Reference to ICE Parameters.
}

\author{
Motey Festus and Dr.Essel Ben Hagan
}

\section{NOMENCLATURE}

ICE Internal Combustion Engine

\section{Abstract}

Heat produced in ICEs is from two sources, thus friction and internal combustion of liquid fossil fuel exclusively in combustion chamber. Cooling system of ICE consists of components assembled to maintain and reduce total heat to manufacturers' recommended value or range. This cooling system makes use of water in combination with additives as working material that flows through galleries carrying heat away.This cooling system recirculates cooling water through engine block. Only about one - third of this total heat energy is used by automobile motion, whiles the rest flows through tailpipe as exhaust waste. Radiator, coolant, radiator fan, hoses, pump, heater core, temperature knob, temperature control valve, thermostat, coolant tank, temperature gauge and temperature sensors are components of ICE cooling system.

Objectively, this research will use method of modeling and simulation as well as factors or variable parameters to improve operating conditions of cooling systems. Thus, there will also be improvement in reduction of heat generation as well as rate of liquid fuel consumption reduction.Therefore, these modeling as well as simulation results will produce graphical trends for conclusions and recommendations.

Key words: Coolant; Radiator; Combustion; Automobile; Temperature.

\section{INTRODUCTION}

One - third of total energy produced during internal combustion processes becomes waste and given to cooling system to be blown away as heat. Approximately, when a gallon of fuel is burnt or internally combusted, nineteen thousand joules to twenty thousand joules $(19,000 \mathrm{~J}-20,000 \mathrm{~J})$ of heat will be produced. A system consisting of components and fluid that operate together in ICEs to control total temperature for optimal performance is referred to as cooling system. The quantity of heat produced during internal combustion using one (1) gallon of liquid fuel will approximately boil one hundred and twenty (120) gallons of water.Rebecchi, (2012). This fluid or water that flows through ICE with objective of carrying heat away is referred to as coolant. Coolant must be able to withstand extreme hot as well as cold temperatures. Coolant's following starts from water pump and continues within galleries of ICEs. Brand, (2005). This cooling system averagely contains two (2) gallons of coolant circulating within to carry out portions of total generated heat. Normally, a four cylinder (4) automobile moving at relatively high velocity of about fifty (50) miles per hour will experience four thousand (4000)internal combustion starts in a tight combustion chamber when fuel is ignited by spark plugs.Aken, Williems and Jang, (2007). Thus, these combustions will produce significant quantity of heat which needs to be 
controlled so as to protect ICE. Therefore, the prime function of ICE cooling system is to maintain total temperature at manufacturer's recommended value or range.

Furthermore, unfavourable fuel economic conditions and emissions will result if ICE temperature is too low. Mechanical energy used by automobile for motion is about thirty percent (30\%) of total internal combustion energy produced whiles the rest is waste. After engine startup, within a period of time between three (3) minutes to thirty (30) minutes, there will be engine damage if cooling system fails to work. Objectively, this article will use the methodology tools of modeling and simulation as well as piston - cylinder liner compact parameters to improve cooling system of ICEs thereby reducing engine temperature and rate of fuel consumption. Best temperature condition for operating ICE or automobile engineis within the range of one hundred and eighty degrees fahrenheit $\left(180^{\circ} \mathrm{F}\right)$ to two hundred degrees fahrenheit $\left(200^{0} \mathrm{~F}\right)$.Walter, (2001).

\section{REVIED LITERATURE}

\section{Components of ICE Cooling System.}

Radiator, coolant, radiator fan, radiator hoses, water pump heater core, temperature knob, temperature control valve, thermostat, temperature gauge, temperature sensor and reservoir or reserve tank are cooling system components of ICE. There are two main types of cooling systems for automobile engines. These are air and water cooling systems. Relatively, few oldautomobile engines such as volkswagen beetle, chevroletcorvair and motorcycles use air cooling system. Thus, air is cooling fluid used in air cooling ICEs. An improvement of air cooling system is water cooling system. Fluid or liquid used in liquid cooling system is water.Arcoumanis and Kamimoto, (2009). ICEs of cars, trucks, among others use liquid cooling system. Meanwhile, some components mentioned are not used by air cooling systems.

\section{Radiator}

Normally, core of radiator consist of flat aluminum tubes with zigzag aluminum strips between these tubes. Transfer of heat in tubes to air, thus to be conducted away from automobile is done by fins. A tank mostly constructed with plastic are used to cover each end of radiator core. These tubes may be horizontally or vertically arranged. Earlier radiators were made of copper whiles their tanks were made of brass. Relatively, modern ICEs have their radiator systems made of aluminum and plastics which were more cheap and efficient. In order to seal radiator systems so as to keep fluid from leaking, particularly for radiators having plastic cups, then gaskets are fixed between plastic tanks and aluminum core. Alternatively, relatively older radiators that were made of copper and brass, there was brazing or welding of tanks in such a way to seal as well as prevent fluid leakage.

All these types of tanks have a large hose connected at top of radiator for coolant flow. At the bottom of radiator is connected another large hose to a different tank for coolant or fluid flow out. There is one additional opening at top of radiator that is capped off by the radiator cap. There is also a separate tank mounted inside one of the tanks for automobile engines that have automatic transmission. The inner tank and automatic transmission are connected by fittings which pass through steel tubes. Thus, in inner tank, transmission fluid in the pipe is cooled by passing cold fluid around it before flowing to transmission. Brace, Slipper - Bumham, Wijetunge, Vaughan, Write and Bright, (2001).

\section{Radiator Fans}

Relatively, older ICEs have one electric fan put in housing, whiles new ICEs have two electric fans in housing. All these fans are located at back of radiator core, thus between radiator and engine. Housing functions by protecting fingers of electric fan and directing air flow towards cells of radiator core. 
Themajor function of fan is to blow hot air in radiator core cells away, thereby cooling hot water for circulation. Relatively old ICEs have their fans powered through fan belts and will always operate any time ICEs are running. This continuous operation occurs because the fan belts operate automatically any time ICEs are switched on, hence fans. Electric motors and sensors are used to drive radiator fan of modern ICEs. Thus, these sensors as well as electric motors operate radiator fans in accordance to engine conditions such as temperature and pressure.Singh, Gara, Kumar and Chaulharu, (2013). Overheating as well as damage will occur when the motors and sensors are not functioning while ICEs are operating. Computer units of ICEs control operations of electric fans. Furthermore, temperature sensors monitor engine temperatures and transmit them as data signals to these computer units. These computer units act as controllers for actuating on and off modes of electric fan motors.

An additional radiator is mounted in front of the normal radiator in cases where ICEs or automobile engines have air conditions. Thus, in these situations, the second radiators are referred to as air condition condensers. The second radiator also needs cooling by air flow. The fan will always be in operation when air condition is on, even if ICE is off. Air must continue to flow through air condition condenser so that there will be cooling of passenger compartment.Choquet, (2014).

\section{Pressure Cap and Reserve Tank}

Heating and expansion of coolant will cause increasing pressure in sealed cooling system. Components of coolant allow cooling temperature to reach high values. A simple device in this cooling system which maintains pressure is radiator cap. As pressure continue to increase above manufacturer's specified value, spring loaded valve with calibration in psi will release excess pressure. A small quantity of coolant is expelled out during this release or when cooling system is malfunctioning. The blend off coolant is trapped by unpressurized plastic tank. That is there is less coolant and vacuum in cooling system. Radiator cap contains a secondary valve that permits created vacuum in cooling system of ICEs to draw trapped coolant into radiator from reserved plastic tank.Ganeshan, (2012).

\section{Water Pump}

Water pump is also referred to as water puller and is mounted in front of the engine. Water pump is driven by a fan belt which also power alternator, power steering, air condition compressor as well as one or more camshafts. Water pump is the device that makes coolant to circulate continuously during ICE operations. This water pump consists of cast iron or cast aluminum housing, a spinning shaft on which an impeller was mounted and a pulley attached to a shaft. This pulley is outside the shaft body.Oduro, (2012). Centrifugal force applications are used by impeller to pull coolant to flow from lower radiator hose into engine block under pressure hose. Coolant flows around spinning shaft inside the housing, but prevented from leaking out of pump housing by application of seal. Also, a gasket acts as seal between engine block and water pump. Thus, to stop flowing coolant from leaking.Janowski, Shayler, Robinson and Goodman, (2011).

\section{Thermostat}

Valve that records temperature measurements of coolant so as to open or close accordingly is referred to as thermostat. Furthermore, when coolant temperature is high enough then thermostat valve will open for hot coolant to flow through radiator. At relatively low temperatures of coolant, coolant flow into radiator is blocked so that a by - pass is developed that permits coolant flow back directly into engine without flowing through radiator. Occurrence of hot spots are prevented and balance of temperatures are kept when this by - pass permits coolant flow through ICEs at manufacturer's recommended temperature. Calibrated thermostat will keep coolant temperatures between one hundred and ninety two 
(192) degrees celsius and one hundred and ninety five (195) degrees celsius resulting to better efficiency of ICEs, reduction of emissions, better fuel economy and higher life span.Vetrovec, (2008). Usually, thermostat is situated in water outlet housing at top front of ICEs. This outlet housing also serves as linkage for upper radiator hose. Heavy paper or rubber O ring is material used to make gasket. Some ICEs have no gaskets but rather thin head special silicone seal is applied between spaces to form seal. The seal copper cup is made up of wax and pellet metal. This wax when subjected to heat will expand resulting to pushing piston to pressure spring as well as opening of valve to allow coolant circulation.Ebrahimi, Chen et al, Ge et al and Rahim, (2010).

\section{Freeze Plugs}

During manufacturing of engine block, sand mold shaped - like coolant passage are placed in the metal castings. This mold forms holes for coolant passage. Steel discs or cups are freeze - out plugs used to plug these holes tightly. When only water is used as coolant, freezing and expansion pressure may cause cracking of ICE block. Freeze plugs will solve problems of pressure and cracking but the steel is subjected to rusting. Anti - freezers lose their effectiveness after three (3) years.Kajiwara, Fujiok and Negish, (2003).

\section{Head Gaskets and Intake Manifold Gaskets}

Space between flat metal surfaces of cylinder head and engine block will permit leakage of fluids. Head gasket must seal these tiny spaces between cylinder head and engine block such that engine oil as well as coolant will easily flow between cylinder and block. Head gasket is usually made of soft sheet metal stamped with ridges to surround all leakages when sandwiched between cylinder head and block. Gasket also helps ICEs to withstand combustion pressure. Cylinder head and engine block are tightened by head bolts passing through them and this ensures sealing. Aging and overheating will cause cracks within gaskets resulting to combustion gases leaking into combustion chamber causing white smoke in tailpipe as well as mixing oil with coolant. $\mathrm{V}$ - shaped engines have two cylinder heads, therefore they have two gaskets. Luff, Law and Shayler, (2012).

\section{Heater Core}

Heater core is made of a small radiator having two pairs of rubber hoses which are connected to cooling system of ICEs. Heat in coolant is supply to vehicles' interior if required. One of these hoses is connected to water pump so as to supply hot coolant to core whiles the other hose return coolant to engine top. Furthermore, heater controlled valve is fixed in one hose so as to regulate coolant flow. Air is drawn through heater core by special fan known as blower. This blower directs air to pass through heater duct to automobile interior component. A blend door regulates hot air with relatively cold air outside so as to obtain required temperature of air entering interior component. Blend doors at floor, windshield and air condition ducts located at instrument panel are used for temperature control with reference to automobile interior.Pang and Brace, (2004).

Components of cooling system are interconnected by many rubber hoses. Majority of these rubber hoses of pumping systems are upper as well as lower radiator hoses. Thus, these two major hoses are responsible for flow of water between radiator and engine block which are about two (2) inches in diameter. Additionally, two hoses known as heater hoses allow hot coolant to flow from engine to heater core. There may be a heater control valve fixed in one of these hoses to regulate flow of hot coolant to heater core if air condition is at maximum cool mode. Diameter of this hose is about one (1) inch. By pass hose is fifth (5th) hose. At neck of reserved bottle is mounted a small hose that permits released 
coolant from pressure cap to flow into reserved tank. Diameter of this rubber hose is approximately one quarter (1/4) of an inch and is not under pressure.Samhaber, Wimmer and Liobner, (2012).

\section{Maintenance and Repair of ICE Cooling System}

At manufacturer's recommended time, coolant must be flushed out and refilledin cooling system. Different metalsof cooling systems have different properties which result to scale. Scale clogs tubes resulting to overheating. Process of scale formation is referred to as corrosion. Antifreeze or anti corrosion agents contain chemicals such as ethylene glycol and propylene glycol that prevent corrosion.Clive, (2007). Antifreeze have life span so must be replaced as recommended. Hoses, belts, thermostat, radiator, heater core, pumps, fan, coolant chemicals and radiator cap are components that must be inspected and replaced as recommended. Brace, Hawley, Akchurst, Piddock and Pegg (2008).

\section{METHODOLOGY}

Cooling systems modeling and simulation is research methodology adopted by this article. Monitoring as well as analyzing cooling systems of ICEs is done by this research through modeling and simulation.Highm and Higham, (2005). Thus, simulation and modeling are employed to objectively improve ICE cooling system when factors of number of piston rings, number of pistons, weight of connecting rod, engine temperature and piston diameter are incorporated into models of this research. Guzzela and Onder, (2010). Thus, this methodology tools will provide results that will be used to show reducing trends of rate of fuel consumption. These models are mathematical equations containing alphabets of cooling system processes as well as components. Chapman, (2004).

Modeling involves writing and running of matlab programs of models for cooling systems using variable alphabets. During simulation of these models, blocks representing essential components or processes are picked from simulink libraries and assembled in new workspace. Guzzela,(2007). These blocks are linked by connecting lines to form cooling systems to be simulated. Factors to be incorporated into these models as well as temperature will be continuously varied during modeling and simulation.Lansky, (2008). Relatively, this methodology is less expensive, more accurate and less time consuming as compared to experimental analysis.Furthermore, this method produces graphical results showing reductions in temperature and rate of fuel consumption indicated in conclusions and recommendations.Moler, (2004).

\section{EQUATIONS FOR COOLING SYSTEMS}

Engine External Cooling

Equation 1

Source: Kanne, (2000).

$$
\stackrel{*}{Q}_{r, \text { in }}=\left(T_{r, \text { in }}-T_{r, \text { out }}\right) \times C_{p c} \times \stackrel{*}{m}
$$

The equation (113) one hundred and thirteen above represents a sub - model for engine external cooling needed (flow of heat to heat exchanger needed).

Where:

$\stackrel{*}{Q}_{r, \text { in }}=$ Heat flow of coolant entering the radiator

$T_{r, \text { in }}=$ Temperature of coolant entering the radiator

$T_{r, \text { out }}=$ Temperature of coolant leaving the radiator

$C_{p c}=$ Heat capacity of coolant

$\stackrel{*}{m}{ }_{r}=$ Mass flow rate of radiator

Heat Transfer 


\section{Equation 116}

Source: Kanne, (2000).

$$
\stackrel{*}{Q_{c, e b}}=z_{c} \times \alpha_{c} \times A_{e b} \times\left(T_{e n g, m}-T_{e b}\right)
$$

The equation (116) one hundred and sixteen above is a sub - model for heat transfer between the coolant and engine block.

Where:

$z_{c}=$ Number of cylinder

$\alpha_{c}=$ Coolant heat transfer coefficient

$A_{e b}=$ Area of engine block

$T_{\text {eng }, m}=$ Temperature of engine cylinder wall

$T_{e b}=$ Temperature of engine block.

Mass Flow Rate

Equation 122

$$
m=D M \frac{1}{B} a A
$$

Source: Martinez, Samchez, Bermudex and Riesco-Avila, (2010)

Equation (122) one hundred and twenty two above is a model for the mass flow rate of fuel.

Where

$\mathrm{V}=$ velocity

$A=$ frontal area

$\mathrm{a}=$ sonic velocity

$\mathrm{P}=$ pressure

$\mathrm{B}=$ bore diameter

Model for Coolant Outlet

Equation 126

Source: Kanne, (2000).

$$
d T_{\text {eng }, \text { out }} / d t=\frac{\stackrel{*}{Q}_{w, c}-\stackrel{*}{Q}_{c, e b}-\stackrel{*}{Q}_{c}}{C_{p c} \times m_{c}}
$$

The above equation is the model for cooling circuit

Where:

$d T_{\text {eng, out }}=$ Change in temperature of coolant leaving the engine

$d t=$ Change with respect in time

$\stackrel{*}{Q}_{w, c}=$ Heat flow from the wall to coolant

$\stackrel{*}{Q}_{c, e b}=$ Heat flow from the coolant to the engine block

$\stackrel{*}{Q}_{Q_{c}}=$ Heat flow from coolant

$C_{p c}=$ Heat capacity of coolant

$m_{c}=$ Mass of coolant

\section{MODELING OF THE EQUATIONS}

Matlab Program for Equation (113) One Hundred and Thirteen.

ㅇODELING FUEL CONSUMPTION REDUCTION IN TERMS OF THERMOMANGEMENT

○MODEL FOR ENGINE EXTERNAL COOLING NEEDED 
DOI : https://dx.doi.org/10.26808/rs.ed.i7v6.11

International Journal of Emerging Trends in Engineering and Development

Issue 7,Vol.6 (October-November 2017) Available online on http://www.rspublication.com/ijeted/ijeted_index.htm

ISSN 2249-6149

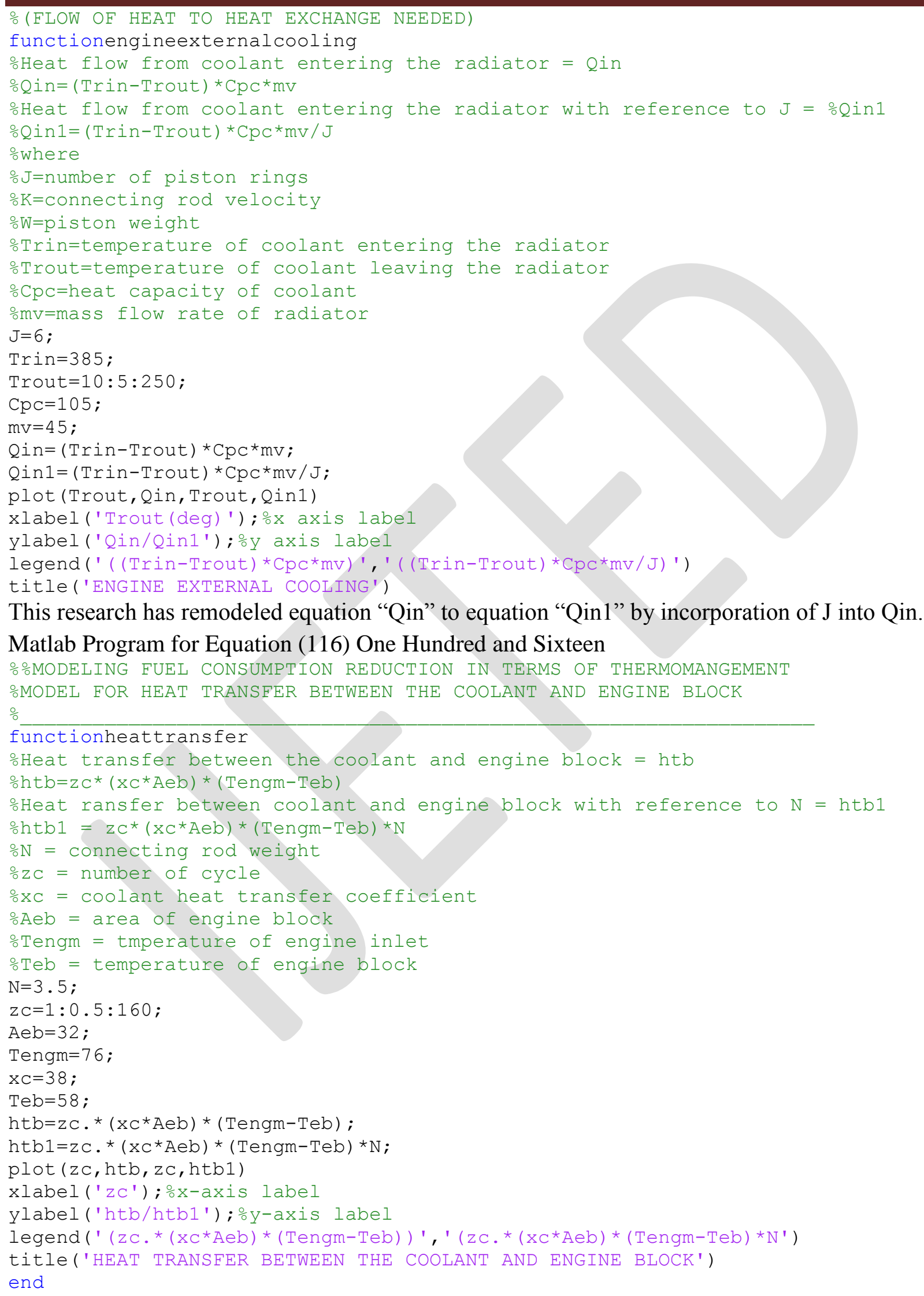

This research has remodeled equation "Qin” to equation "Qin1” by incorporation of J into Qin.

\section{Matlab Program for Equation (116) One Hundred and Sixteen}

음EING FUEL CONSUMPTION REDUCTION IN TERMS OF THERMOMANGEMENT ○MODEL FOR HEAT TRANSEER BETWEEN THE COOLANT AND ENGINE BLOCK

$\div$

functionheattransfer

oHeat transfer between the coolant and engine block = htb

$\circ \mathrm{ht} b=\mathrm{zc}$ * $(\mathrm{xc}$ *Aeb $)$ * (Tengm-Teb)

oHeat ransfer between coolant and engine block with reference to $\mathrm{N}=\mathrm{htb}$

ohtbl $=z_{C} *(\mathrm{xC} *$ Aeb $) *($ Tengm $-\mathrm{Teb}){ }^{*} \mathrm{~N}$

$\div \mathrm{N}=$ connecting rod weight

$\frac{\mathrm{zc}}{\mathrm{C}}=$ number of cycle

$\% \mathrm{xc}=$ coolant heat transfer coefficient

$\therefore$ Aeb = area of engine block

oTengm = tmperature of engine inlet

$\frac{\circ}{0}$ eb = temperature of engine block

$\mathrm{N}=3.5$;

$\mathrm{zC}=1: 0.5: 160$

$\mathrm{Aeb}=32$;

Tengm $=76$;

$\mathrm{XC}=38$;

$\mathrm{Tel}=58$;

htb $=\mathrm{zc} \cdot *(\mathrm{xc} *$ Aeb $)$ * (Tengm-Teb) ;

$h t b 1=z c \cdot *(x c * A e b) *($ Tengm - Teb $) * N$;

plot (zc, htb, zc, htb1)

xlabel ('zC'); $\circ \mathrm{x}$-axis label

ylabel ('htb/htbl'); $\% y$-axis label

legend (' (zc.* (xc*Aeb)* (Tengm-Teb) ) ', ' (zc.* (xc*Aeb)* (Tengm-Teb)*N' )

title('HEAT TRANSFER BETWEEN THE COOLANT AND ENGINE BLOCK')

end 
DOI : https://dx.doi.org/10.26808/rs.ed.i7v6.11

International Journal of Emerging Trends in Engineering and Development

Issue 7,Vol.6 (October-November 2017) Available online on http://www.rspublication.com/ijeted/ijeted_index.htm

ISSN 2249-6149

Analyzing equation "htb" was done by the previous author but has been remodeled by this research to form equation "htbl" through the incorporation of $\mathrm{N}$.

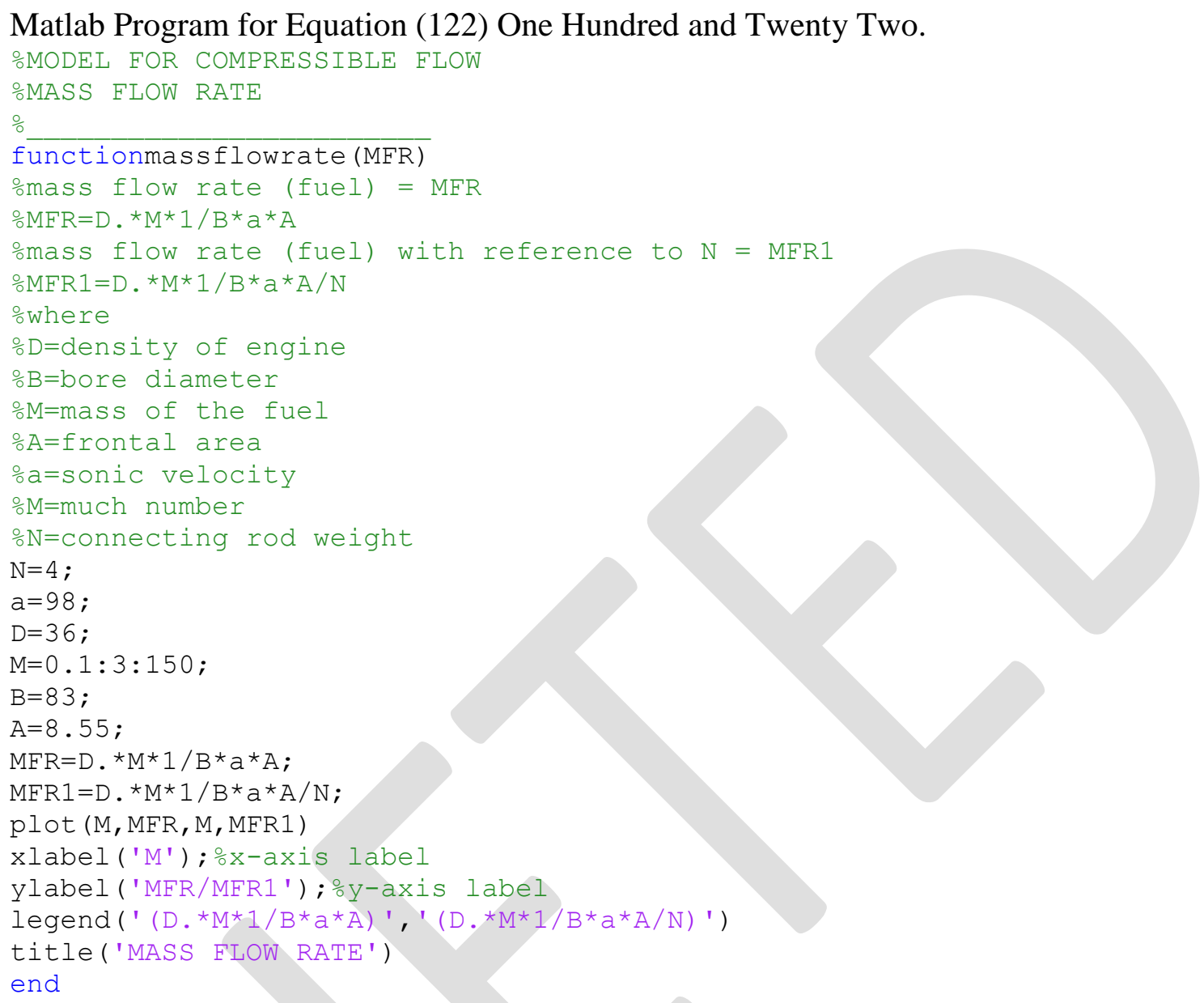

The remodeling of equation "MFR" by this research involves incorporating $\mathrm{N}$ to form the equation MFR1.

Matlab Program for Equation (126) One Hundred and Twenty Six

음ㄴING FUEL CONSUMPTION REDUCTION IN TERMS OF THERMOMANGEMENT

MODEL FOR COOLANT OUTLET

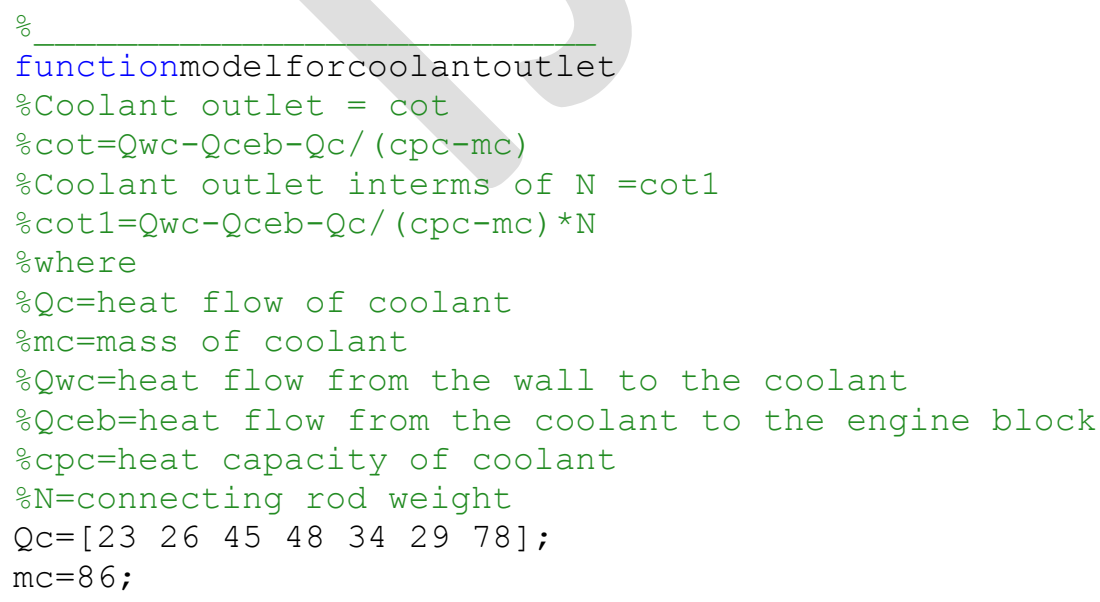


DOI : https://dx.doi.org/10.26808/rs.ed.i7v6.11

International Journal of Emerging Trends in Engineering and Development Issue 7,Vol.6 (October-November 2017) Available online on http://www.rspublication.com/ijeted/ijeted_index.htm

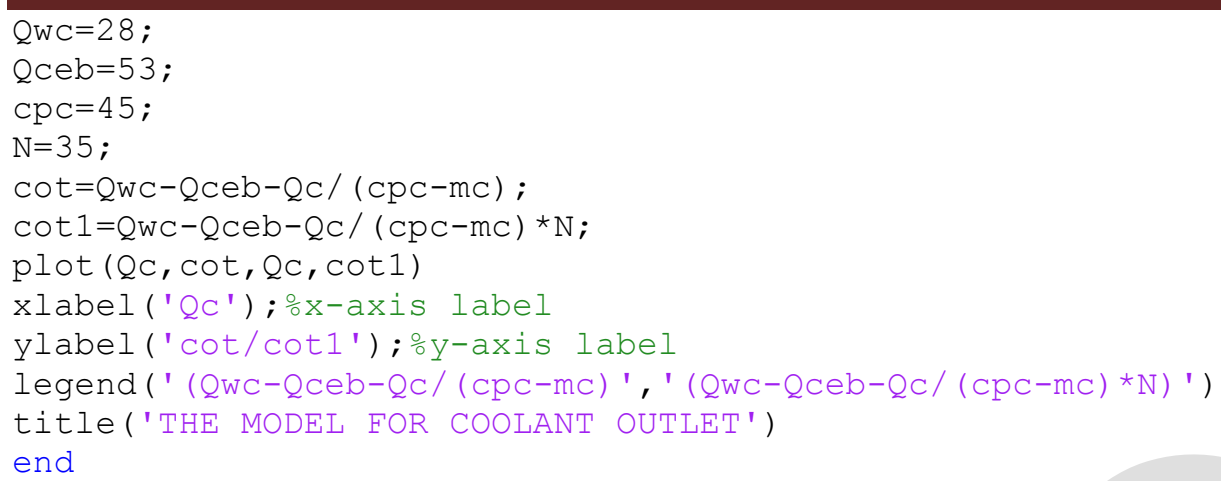

The remodeling of equation "cot" by this research involves incorporation of $\mathrm{N}$ to form "cot1".

\section{SIMULATION OF THE EQUATIONS}

Simulation scheme for equation 113

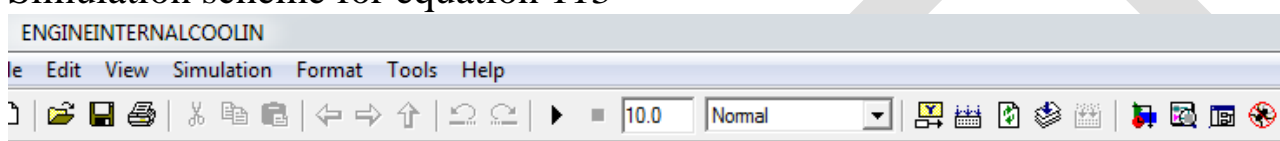

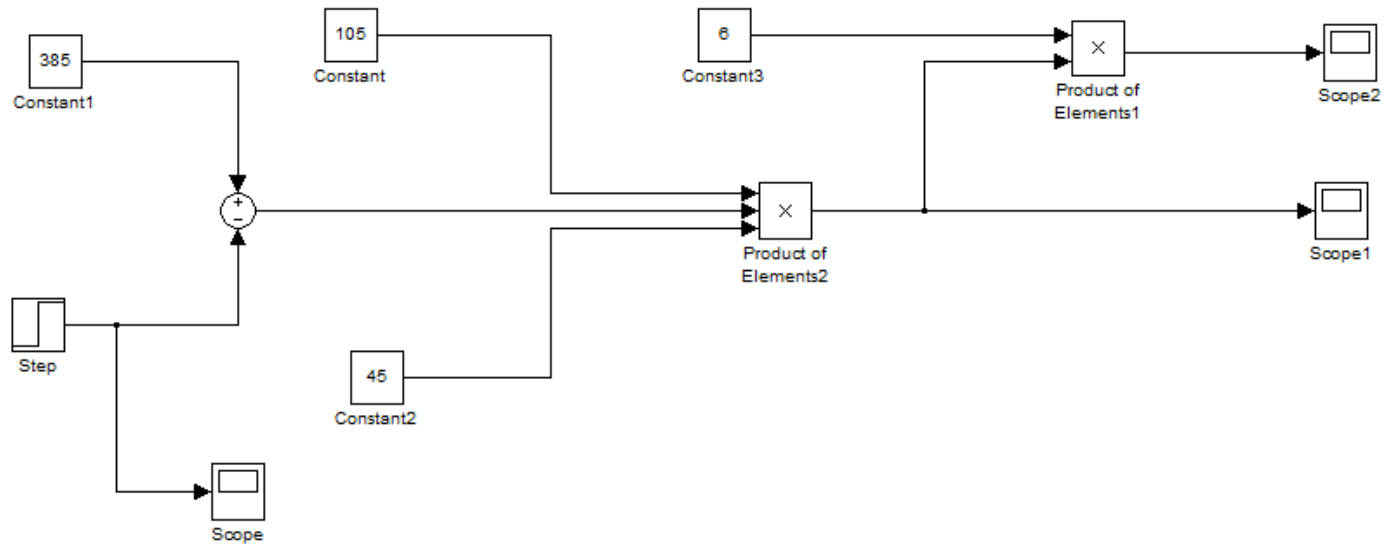

Simulation scheme for equation 116
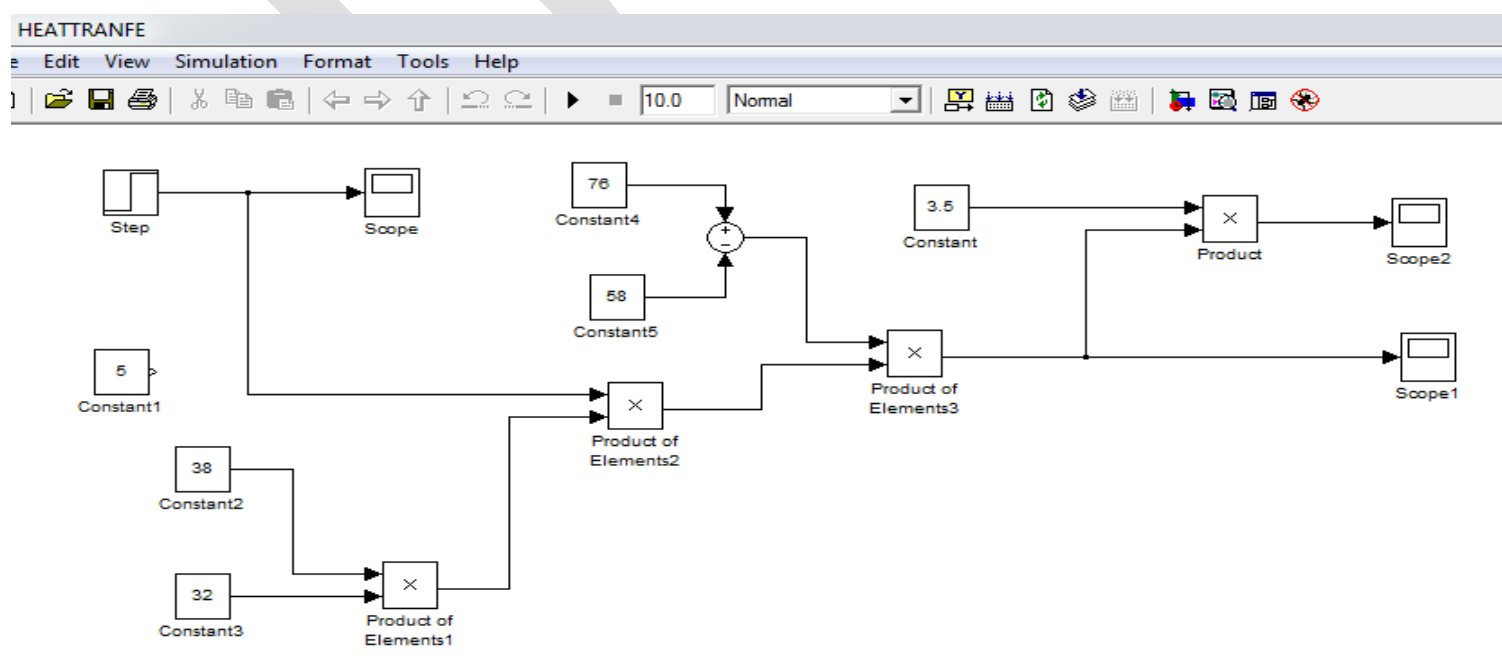
Simulation scheme for equation 122

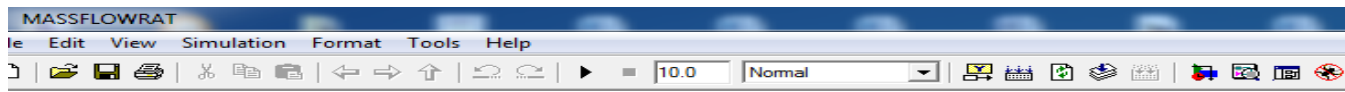

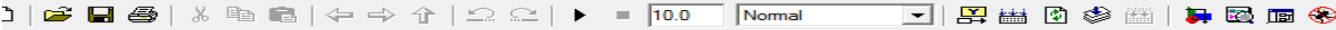

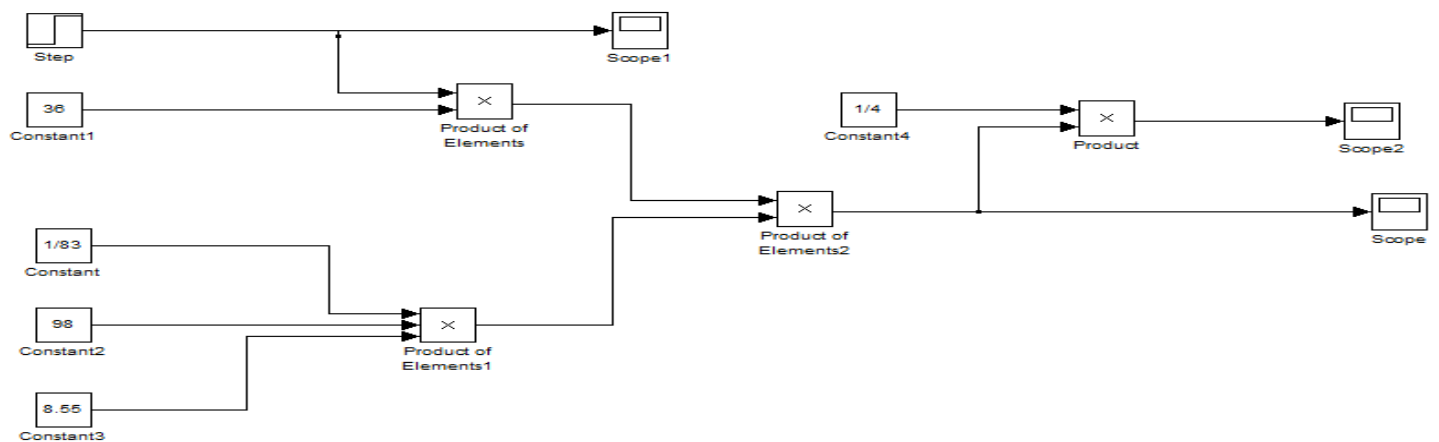

Simulation scheme for equation 126
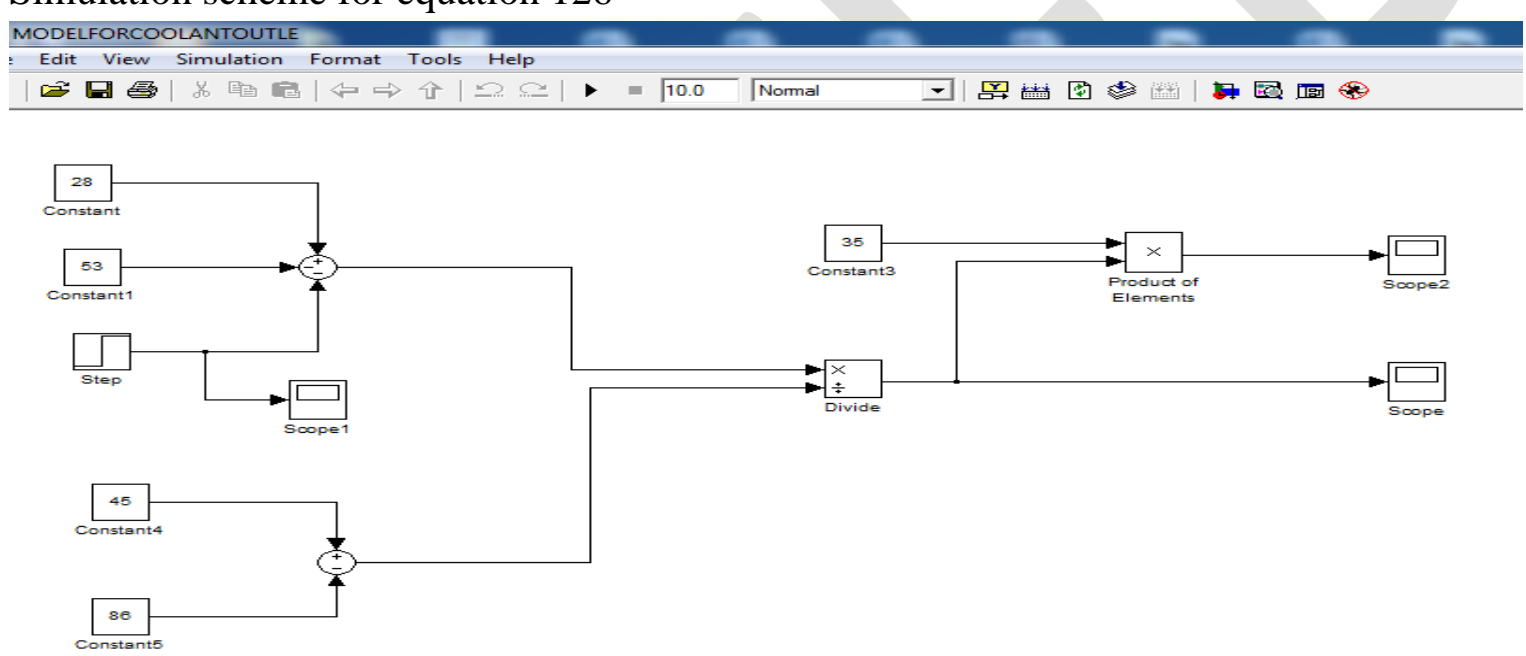

\section{MODELING RESULTS}

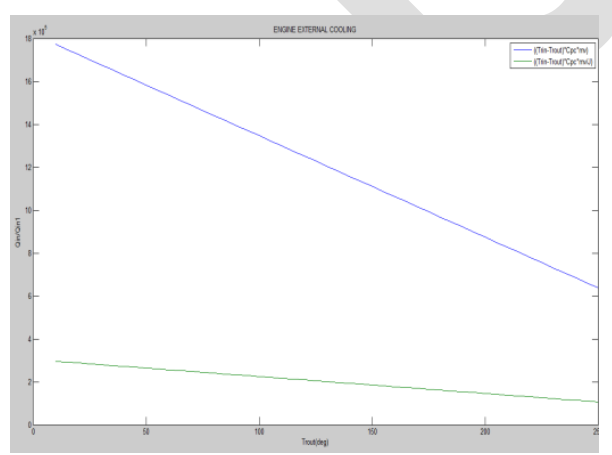

Modeling results for equation 113

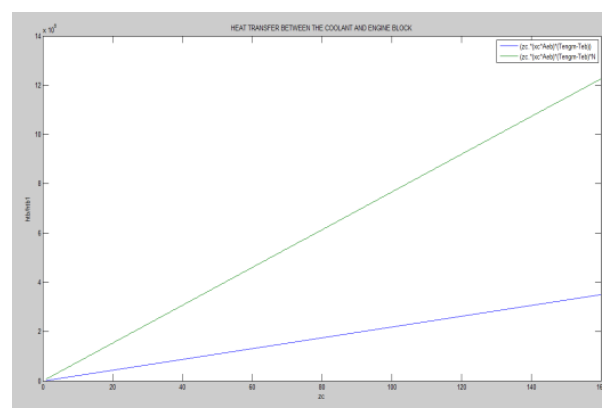

Modeling results for equation 116 


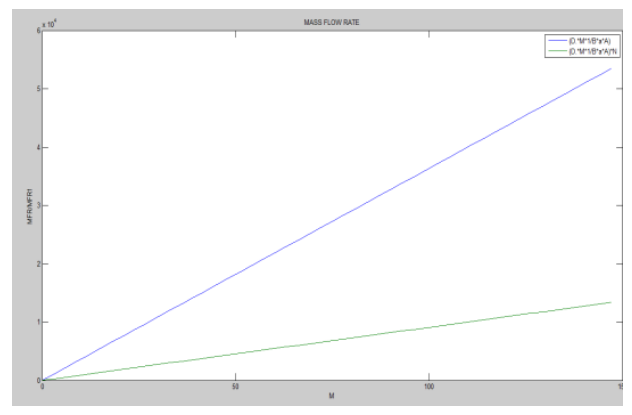

Modeling results for equation 122

\section{SIMULATION RESULTS}

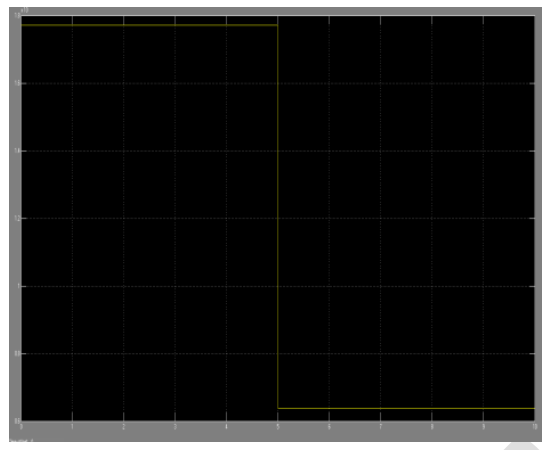

Simulation result i for equation 113

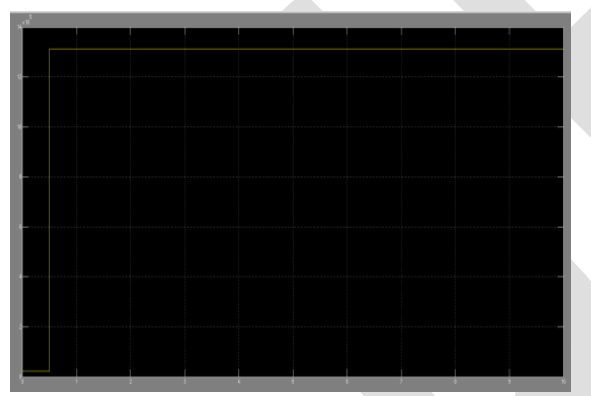

Simulation result i for equation 116

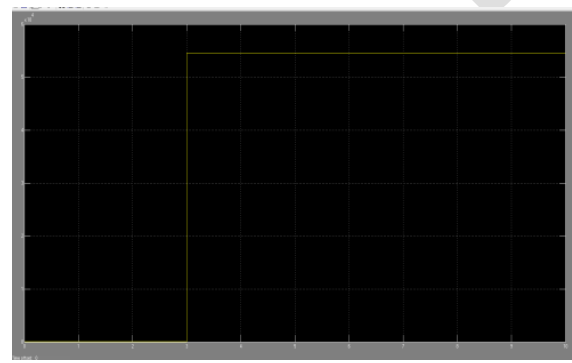

Simulation result i for equation 122

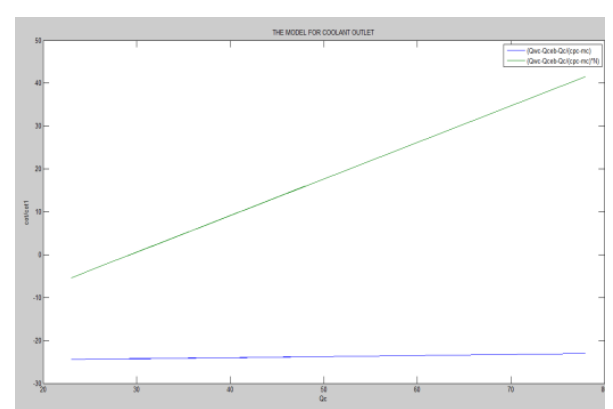

Modeling results for equation 126

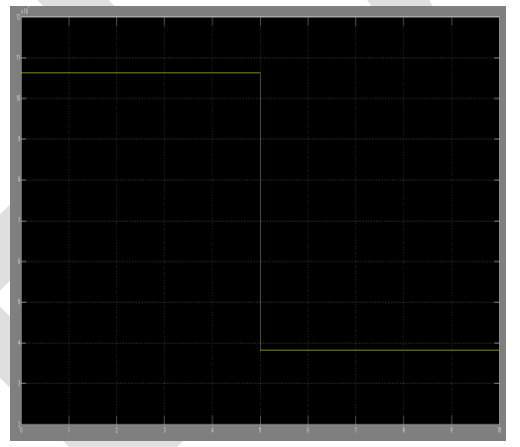

Simulation result ii for equation 113

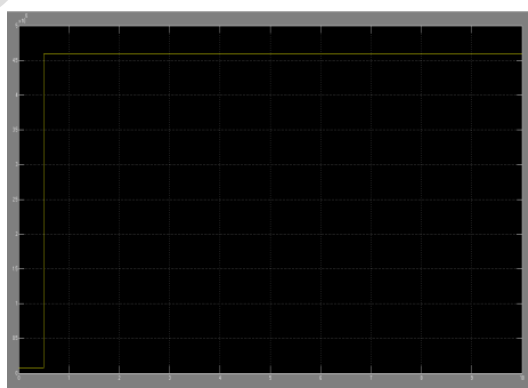

Simulation result ii for equation 116

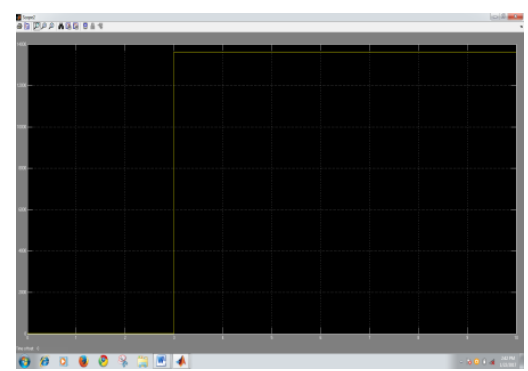

Simulation result ii for equation 122 


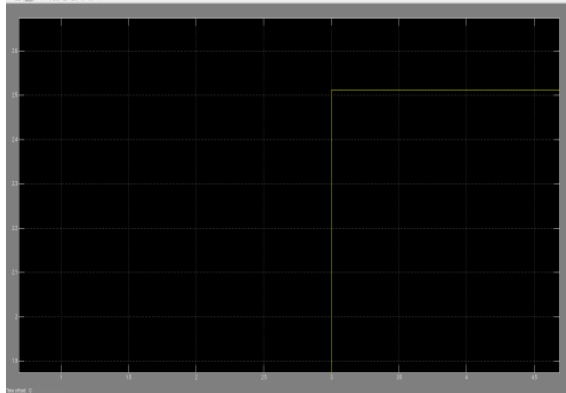

Simulation result i for equation 126

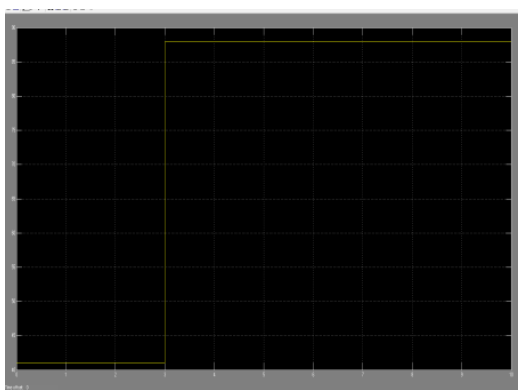

Simulation result ii for equation 126

\section{ANALYSIS OF RESULTS}

Initially, parameter values of piston diameter, number of piston, number of piston rings, engine temperature and weight of connecting rod were incorporated into the equations or models before remodeling so as to observe effects of these parameters on performance of ICEs (cooling systems). Graphical results obtained after the remodeling will indicate effects of these parameters on ICE cooling system which may result to temperature as well as rate of fuel consumption reduction. Efficiency of cooling systems will have direct effect on total temperature of ICEs. Simulation results ii for all the models or equations are obtained after incorporation of individual engine parameters before simulation. Results of modeling equation 113 reveal that relatively less external cooling is needed for efficiency as green line is more below blue line. This implies that after parameter remodeling effect on cooling system, external cooling is low with high efficiency and resulting lower temperature. Equation 116 results after the remodeling indicate higher heat transfer from block to coolant resulting to fast heat removal, lower heat effect on cooling system, lower engine temperature and lesser fuel consumption. Equation 122 results after remodeling shows mass flow rate of coolant has increased, therefore more heat is taken away from ICE. Thus temperature is lower and less fuel is consumed.Modeling results for equation 126 indicate rise in coolant outlet dynamics with respect to ICE parameter. Thus, more heat is carried away from ICE resulting to lower engine temperature, efficient cooling system and lesser rate of fuel consumption.

Simulation result ii for equation 113 shows drop of external cooling required due to incorporation of engine parameter into the model, hence lower effect of cooling system on engine temperature. Result ii for equation 116 simulation implies more heat flow out of ICE, therefore less effect of cooling system on temperature. Simulation result ii for equation 122 indicates rise of mass flow rate of coolant, which implies lower temperature due to cooling system as well as lower rate of fuel consumption. Simulation result 126 ii reveals increase in coolant outlet dynamics, thus less heat is retained so that temperature is low to enable relatively lower rate of fuel consumption.

\section{CONLUSION AND RECOMMENDATION}

Incorporation of the parameter values into these equations for modeling and simulation shows less effect of cooling system on temperature. More research should be done using other ICE parameters and other methods. 


\section{REFERENCES}

1. Aken, M,V., Williems, F. and Jang, D. D. (2007). "Appliance of High EGR Rates with a Short and Long Route EGR System on Heavy Duty Diesel Engine".Journal for Society of Automobile Engineers, paper $01-0906$.

2. Arcoumanis, C. and Kamimoto, I. (2009)."Flow and Combustion in Reciprocating Engines".Springler - Verlag, Berlin Heidelberg.

3. Brace, C. J., Hawley, G., Akchurst, S., Piddock, M. and Pegg, I. (2008). "Cooling System Improvement - Assessing the Effect on Emission and Fuel Economy". Proceedings of the Institution of Mechanical Engineers, Part D, Journal of Automobile Engineering, volume two hundred and twenty two (222), pp. $579-591$.

4. Brace, C. J., Slipper - Bumham, H., Wijetunge, R. S., Vaughan, N. D., Write, K. and Bright, D. (2001). "Integrated Cooling System for Passenger Vehicle". Journal for Society of Automobile Engineers, $01-1248$.

5. Brand, D. (2005). Control - Oriented Modeling of NO Emissions of Engines. Doctoral Thesis, Swiss Federal Institute of Technology, Zurich.

6. Chapman, S. J. (2004). MATLAB Programing Engineers. Thomson (Publisher).

7. Clive, L. (2007). "One Dimensional Modeling of an Internal Combustion Engine".Mekanikfordjupning (Publisher).

8. Choquet, V. (2014). Integrated Engine Waste Recovery by Combustion of Evaporated Engine Cooling and Ranking Bottom Cycle, Application to Heavy Duty Engines. KTH.

9. Ebrahimi, Chen et al, Ge et al and Rahim, E. (2010)."Effects of Gasoline - Air Equivalence Ratio on Performance of an Otto Engine".Journal of America Science, Marsland Press.

10. Ganeshan, V. (2012).Internal Combustion Engines. Tata Macgraw - Hill (Publisher), New Delhi.

11. Guzzela, L. (2007). "Modeling and Control of Advance Propulsion System". Oil Gas Science and Technology, 62, pp. $585-594$.

12. Guzzela, L. and Onder, C. H. (2010).Introduction to Modeling and Control of Internal Combustion Engine Systems. $2^{\text {nd }}$ Edition Springer Verlag, Berlin.

13. Highm, D. J. andHigham, N. J. (2005). MATLAB Guide, Second Edition, Siam (Publisher).

14. Janowski, P., Shayler, P. U., Robinson, S. and Goodman, M. (2011). "The Effectiveness of Heating Parts of the Powertrain to Improve Vehicle Fuel Economy during Warm - up". VTMS 10.

15. Kanne, E. C. (2000). Engine Thermomangement for Fuel Consumption Reduction.Doctorial Thesis, Swiss Federal Institute of Technology, Zurich

16. Kajiwara, H., Fujiok, A. and Negish, H. (2003)."Prediction of Temperature of Piston with Cooling Gallery in Diesel Engine Using CFDTool". Journal for Society of Automobile Eegineers, $01-0986$.

17. Motey, F. (2017).Modeling Fuel Consumption under Changing Temperature Conditions by ICE.Ongoing PhD Thesis, AIT/OUM.

18. Lansky, L. (2008). "Diesel Engine Modeling and Control”.Czech Technical University, Prague.

19. Luff, D. C., Law, T. and Shayler, P. J. (2012).“The Effect of Piston Cooling Jets on Diesel Engine Piston Temperature Emissions and Fuel Consumption". Journal for Society of Automobile Engineers, $01-1212$.

20. Martinez, S., Sanchez, F., Bermndex, V. and Riesco - Avila M. J. (2010)."Liquid Spray Characteristics in Diesel Engines". Sciyo

21. Moler, C. B. (2004).Numerical Computing with MATLAB. Siam (Publisher).

22. Oduro, S. D. (2012). "Assessing the Effect of Dirt on Engine Radiator in the Engine Cooling System". International Journal of Automobile Engineering,Volume (2) two. 
23. Pang, H. H. and Brace, C. J. (2004). "Review of Engine Cooling Temperature on the Performance of a Four Cylinder 1100cc Engine Employing a Dual Circuit Cooling". Institute of Mechanical Engineers, Part D. Journal of Automobile Engineering, volume two hundred and eighteen (218), pp. $1209-1215$.

24. Rebecchi, P. (2012). Fundamentals of Thermodynamics for Pressure - Based Low Temperature Premixed Diesel Combustion Control. PhD Thesis, University of Stuttgart.

25. Samhaber, C., Wimmer, A. and Liobner, E. (2012).“Modeling of Engine Warm - up with Integrating of Vehicle and Engine Cycle Simulation". Journal for Society of Automobile Engineers, $01-1679$.

26. Singh, O. P., Gara, M., Kumar, V. and Chaulharu, I. V. (2013)."Effect of Cooling System Design on Oil Temperature". Journal of Applied Fluid Mechanics, volume six (6), number one (1), pages 61 71.

27. Vetrovec, J. (2008). "Engine Cooling System with a Heat Load Averaging Capability".Journal for Society of Automobile Engineers, 0 - 1168.

28. Walter, J. (2001). Automotive Cooling System Component Interactions. PhD Dissertation, Texas Technical University. 